\title{
A CONSTRUÇÃO DO GENOGRAMA DE FAMÍLIAS GUARANI-MBYÁ: UMA ESTRATÉGIA PARA FORTALECIMENTO E RECONHECIMENTO DE UMA COMUNIDADE INDÍGENA DE CULTURA ANCESTRAL
}

\author{
Neusa Maria CARVALHO* \\ Valquíria Pezzi PARODE ${ }^{* *}$ \\ Marli Olina de SOUZA ${ }^{* * *}$
}

RESUMO: A pesquisa foi realizada em uma comunidade Guarani, às margens da RS 040, no município de Capivari do Sul/RS, com uma comunidade de 40 indivíduos, que se encontram em situaçáo de vulnerabilidade social e cultura. Trata-se de uma pesquisa que se constitui por uma abordagem qualitativa descritiva, que se utiliza do método estruturalista-funcionalista (PARSONS, 1902-1979) e (MERTON, 1910-2003) de investigação e da pesquisa-ação (TIOLLENT,1947) enquanto metodologia, para articulação teórico-prática e análise dos dados da pesquisa etnográfica. Utiliza-se como ferramenta a construçấo do genograma familiar (MC GOLDRICK, 2012) e do ecomapa (MC GOLDRICK, 2012)

\footnotetext{
* Doutoranda em Terapia de Casa e Família. CAIFCOM - Centro de Ensino, Pesquisa e Atendimento do Indivíduo, Família e Comunidade e Faculdade Evangélica do Meio Norte - Pós-graduaçáo em Terapia da Casa e Família. Porto Alegre - RS - Brasil. 90550070 - neusabpinhal@gmail.com

** UERGS - Universidade Estadual do Rio Grande de Sul. Porto Alegre - RS - Brasil. 90010-191. Doutora em Educação. PUCRS - Pontifícia Universidade Católica do Rio do Grande do Sul. Porto Alegre - RS - Brasil. 90619-900. Socióloga e Artista Plástica. UFRGS - Universidade Federal do Rio Grande do Sul. Porto Alegre - RS - Brasil. 90040060. Psico-Terapeuta e Coaching Multidimensional - vpezziparode@yahoo.com.br

*** Doutoranda em Terapia de Casa e Família. CAIFCOM - Centro de Ensino, Pesquisa e Atendimento do Indivíduo, Família e Comunidade e Faculdade Evangélica do Meio Norte - Pós-graduação em Terapia da Casa e Família. Porto Alegre - RS - Brasil. 90550070 -marli@caifcom.com.br
} 
da comunidade, norteados por um questionário estruturado, visando à escuta da voz desses sujeitos. A análise dos dados traz reflexóes hermenêuticas e semióticas, à luz dos conceitos de Gadamer (1900 - 2002) e Peirce (1839-1914), por uma perspectiva histórica e cultural, estabelecendo um diálogo com autores da Terapia Familiar Sistêmica. Por fim, nas consideraçóes finais, a importância cultural dos Guaranis para a sociedade contemporânea, bem como as possibilidades da utilização do genograma como ferramenta de atendimento das comunidades e famílias, tanto no enfoque terapêutico, quanto para formulação ou estruturação de políticas públicas.

PALAVRAS-CHAVE: Cultura. Guarani. Família. Genograma. Comunidade indígena.

\section{Introduçáo}

Esse estudo se configura a partir da atividade docente da pesquisadora, desenvolvida na Escola Estadual Indígena de Ensino Fundamental Arandua, implantada em maio de 2013, na Aldeia Araçaty, localizada na RS 040, próxima à Ponte do Rio Capivari, no município de Capivari do Sul, no Estado do Rio Grande do Sul. Trata-se de uma pesquisa de doutorado, que se constitui por uma abordagem qualitativa descritiva. Apresenta reflexôes sobre a organizaçáo familiar do indígena da etnia Guarani-Mbyá, juntamente com o relato e análise das experiências vivenciadas, ao construir o genograma ${ }^{1}$ familiar e o ecomapa ${ }^{2}$ da comunidade.

O "jeito de ser" - característico dessa comunidade - se expressa na simplicidade do "estar juntos", na harmonia de ser e conviver, na arquitetura das casas que contrasta com a vulnerabilidade originada pela ausência de energia elétrica, de políticas públicas de saneamento, bem como pela morosidade na demarcação de território; fatos que despertam humanidade, solidariedade, ao mesmo tempo que, curiosidade, justamente quando o exercício profissional de docência da pesquisadora inicia-se nesse espaço

\footnotetext{
Genograma, segundo McGoldrick (2012, p.21), constitui-se em um mapa padronizado que "[...] está se transformando em linguagem comum para rastrear a história e os relacionamentos da família."

2 Ecomapa: consiste em uma representação gráfica das ligaçōes de uma família às pessoas e estrutura social do meio em que habita, revelando os seus mecanismos de apoio e equilíbrio com a comunidade onde está inserida, mostrando as necessidades e os recursos da família (AGOSTINHO, 2007, p.327).
} 
e a $11^{\text {a }}$ Coordenadoria de Educação decide, em comum acordo com as lideranças, implantar uma escola de ensino fundamental para escolarização dessa população.

Porquanto, inicialmente, apresentar-se-á a comunidade em estudo para contextualização dos sujeitos, território físico e cultural, juntamente com o ecomapa e os genogramas familiares, seguindo com discussões, análises e reflexôes sobre a organização familiar, limites, fronteiras, os papeis e as funçôes dos membros do sistema familiar e comunitário, observando as contribuiçóes que essa forma de viver traz para o sujeito indígena: resistência, resiliência e sofrimentos. Buscar-se-á uma compreensão hermenêutica a respeito deste sujeito, olhando-o, enquanto "[...] forjado a partir do mundo, mais precisamente, a partir da tradição de sentido onde ele está situado.”, conforme conceito de hermenêutica desenvolvido por Gadamer (1983) apud Costa e Grün (2007, p.95).

Com essa contextualização, processar-se-á a escuta da palavra falada e da palavra vista pelo desenho, visando à valorização e o reconhecimento da oralidade desse povo, que se comunica pelas "belas palavras", pois, conforme estudos de Chamorro (2014), no artigo "Língua e Identidades: Desafios da Palavra Guarani ao TekoArandu”,

[...] os sábios e as sábias guarani dizem que o ser humano é, em sua origem, uma palavra sonhada. A mulher para engravidar sonha a palavra. Quando chega a hora de dar à luz, o Verdadeiro Pai e a Verdadeira Mãe das palavras-alma dizem para a palavra-alma que está por nascer: Vá a terra, meu filho (minha filha), eu farei que minha palavra circule por teus ossos e que tu te lembres de mim no teu ser erguido.

$\mathrm{Na}$ hermenêutica - palavra que em grego pode ser traduzida por interpretar - encontra-se a possibilidade de compreensão desse sujeito indígena contemporâneo, dentro de uma perspectiva de pesquisa que traz em sua essência a linha de pesquisa dos filósofos gregos, que pretendiam não a dominação dos objetos, mas o seu conhecimento, deixando "fluir" através da observância dos acontecimentos e do contexto que permeiam a interação entre o pesquisador e os sujeitos envolvidos, guiando o curso das reflexôes.

Não dominavam os objetos, mas eram dominados por eles. A ideia grega de arte, por exemplo, implica que a própria atividade artística é participação na criação da verdade. Quando o artista ajuda a libertar 
o que já está na obra, esse processo de produção de arte mexe com o autor. Nesse sentido, o logos, para os gregos, não consistia em um processo de racionalizaçáo a partir da razão humana. O logos representava uma ordem cosmológica dentro da qual o próprio homem deveria encontrar o seu devido lugar. (COSTA; GRÜN, 2007, p.86).

Essa pesquisa constitui-se assim, numa metáfora: uma "longa e prazerosa caminhada" na cosmologia dos Guarani-Mbyá, de forma que, ao se caminhar e estabelecer um diálogo entre os dois mundos (indígena e náo indígena), se produz reflexóes dentro do enfoque da Terapia Familiar Sistêmica, de modo singular, revelando que estamos sendo tocados pela experiência de "estar juntos".

A segunda parte da pesquisa constitui-se na contextualização do sujeito indígena na sociedade contemporânea, apresentando o lugar do índio na legislação vigente, bem como reflexóes sobre a invasão dos problemas atuais enfrentados pela comunidade. Ao refletir sobre a cultura e o lugar do indígena na legislação brasileira, visa-se abrir canais de comunicação e aproximação entre esses dois mundos traçando o caminho histórico familiar, comunitário e social das famílias, resgatando a importância cultural da ancestralidade deste povo.

A terceira parte apresenta reflexóes sobre o trabalho desenvolvido na experiência da pesquisa-ação, na qual se constituiu essa pesquisa, onde cada sujeito tem oportunidade de encontrar o seu lugar para expressão, coexistindo com a sua palavra "erguida", com a firme convicção de que se é um ser divino, integrado ao cosmos, único, livre e independente e, ao mesmo tempo, selvagem e dependente, deixamos que os sujeitos observados e a sensibilidade da pesquisadora guiassem o curso das ideias dentro da cosmologia vivida. "A vida humana é condicionada e contextualizada pelo fenômeno da linguagem, da cultura e da política." (COSTA; GRÜN, 2007, p.94).

Posteriormente, as consideraçóes finais, que se configuram de forma reflexiva, num enfoque hermenêutico e semiótico, conforme pressupostos da Terapia Familiar Sistêmica, segundo os quais é pela historicidade e simbologia, pela escuta da palavra e significados, pela convivência ética que surgem possibilidades, para novos estudos, para conhecimento dos processos de manutenção e adaptação das comunidades tradicionais; oportunizando o reconhecimento pela sociedade envolvente, do quanto a cultura ancestral dos Guarani-Mbyá pode contribuir com a qualidade de vida, independente da matriz cultural originária de cada sujeito. 


\section{Aldeia Araçaty: uma comunidade Guarani-Mbyá}

A Aldeia/TekoáAraçaty está localizada às margens da RS 040, nas proximidades do quilômetro 060, antes da Ponte do Rio Capivari, para quem vem no sentido Porto Alegre - Litoral. Atualmente, vivem nesta aldeia, organizada em forma de acampamento, em torno de 11 famílias, agrupando aproximadamente 40 pessoas, entre adultos e crianças. As casas são distribuídas ao longo da RS 040, algumas são feitas de bambu, lonas e panos; porém a grande maioria é de madeira doada pela FUNAI Fundação Nacional de Apoio ao Indígena: todas foram/são construídas pelos indígenas com auxílio dos pescadores (que procuram abrigo ou moram próximo da aldeia, também de forma ilegal), incluindo a edificação da escola, denominada EEIEF Arandua. Sua construção foi realizada pelos Guarani-Mbyá com auxílio destes pescadores, em maio de 2013, data em que a pesquisadora chegou na aldeia.

$\mathrm{O}$ viver na aldeia é tranquilo. Os indígenas sobrevivem da venda de artesanato, doaçôes e alguns membros possuem salário por serem executores de políticas públicas, entre eles o professor indígena, a merendeira e a agente de saúde indígena. Outros, por já estarem com idade avançada recebem o benefício de aposentadoria. Todos são indicados pelo cacique: até mesmo a função de professora passou por sua aprovação.

O guarani é de muita escuta e pouco falar, especialmente com os não indígenas, até por que tendo o português como sua segunda língua, alguns membros possuem dificuldades de entendimento.

As doaçôes são recebidas pelas crianças e mulheres; os homens mantêm-se à distância e reservados. Porém, quando a visita é para olhar ou fotografar a aldeia, ou ainda, os pregadores das diferentes religióes, esses são recebidos pelos homens ou pelas mulheres mais jovens, casadas, que dominam melhor a língua portuguesa. A autoridade dos adultos é harmoniosa e claramente perceptível: pelo olhar, uma criança só cumprimenta dando a mão se for autorizada, entre outras situaçóes.

Durante o período de pesquisa e o desenvolvimento das atividades de docência, não é possível explicar ou saber seus combinados. Porém, em vários momentos, sente-se quando decidem mostrar um pouco do seu viver, fazem-no em conjunto e sincronicamente: "Vou levar ela para pescar", trocando olhares de entendimento. Em alguns dias, ao chegar à escola, percebe-se os recados através dos desenhos, ou de livros deixados abertos em determinada página, inclusive no pátio da Aldeia.

Observa-se grande respeito pelos mais velhos, assim como pelas mulheres. Nunca se presenciou qualquer malícia ou insinuação em virtude 
de exposição do corpo, tratam-se com muita naturalidade e conservam, dentro do possível, o viver integrado com a natureza. Na época das chuvas e dias quentes é comum o banho das crianças "como antigamente", que interagem entre si. Em caso de conflito, o adulto somente separa ou tira o objeto perigoso, em silêncio, sem repreensóes ou discussóes. Pode-se dizer que durante todo o tempo da pesquisa presenciou-se somente uma "discussão" ou "um falar mais alto" de uma das indígenas com o seu genro em virtude de um conflito entre o casal. Depois disso, passada uma semana, em um dia de chuva, ao chegar à aldeia observou-se essa avó cuidando dos netos, enquanto o jovem casal vinha caminhando pelo acostamento da RS, cada um com um feixe de lenha nas costas, o que pareceu um ensinamento do viver a dois, na ajuda mútua e na valorização de um pelo o outro.

No viver diário demonstram imenso respeito pela família e pelo modo de ser de cada um. Aguardam pacientemente a demarcação das terras pela FUNAI, convivem em harmonia com o entorno. A visão que se registra dos Guarani-Mbyá é de um povo ordeiro, com uma imensa tradição cultural, mas que aprendeu a cultivar os seus saberes no escondido, fazendo inclusive uma "cortina de sujeira" para afastar os não indígena ou juruás, como denominam os brancos. Em alguns momentos reproduzem o que se denomina como traumas históricos: "sou indígena, vivo na beira da estrada, pois o branco veio e tirou tudo de nós", fala de um dos alunos adulto em uma das atividades na escola, quando produziu um crachá com seu nome e um desenho significativo.

$\mathrm{Na}$ compreensão do significado destas expressôes, suas revelaçôes sobre o sofrimento deste cidadão: indígena do mundo contemporâneo, que já sofre dependência do alcoolismo, torna-se necessário o processo reflexivo com contextualização histórica ontológica deste ser, dentro do enfoque hermenêutico trazido por Gadamer (1997, p.158), como a observação de um quadro, e buscando na imagem da tela o contexto do artista e do tempo em que ele foi pintado.

Um quadro, portanto, não é, certamente, um sinal. Mesmo a lembrança, na verdade, não permite que alguém se demore junto de si, mas junto ao passado que a lembrança apresenta a ele. O quadro, em contraposição, realiza sua referência ao representado apenas através deseu próprio conteúdo. Ao nos aprofundarmos nele, chegamos, ao mesmo tempo, ao representado. O quadro referencia, na medida em que permite que nos demoremos nele. Pois é isso que perfaz aquela valência de ser, que acentuamos que não está separada daquilo que 
representa, mas que participa de seu ser. Vimos que o representado se torna ele próprio no quadro.

O indígena, neste contexto, torna-se aquilo que verdadeiramente éSer parte da terra - visto que a questão territorial é importantíssima para a sustentabilidade do povo, que caminha em busca da terra sem males, ou um lugar bom para viver, inspirados pelos mais velhos ou pajés (lideranças religiosas). A compreensão desse sujeito precisa ser entendida como parte da ocorrência de todo o massacre do povo. Assim, busca-se apoio na arte literária para tentar ampliar o significado do que se fala através de parte do poema Uraguai de Basílio da Gama (1769):

\author{
Fumam ainda nas desertas praias \\ Lagos de sangue tépidos e impuros \\ Em que ondeiam cadáveres despidos, \\ Pasto de corvos. Dura inda nos vales \\ O rouco som da irada artilharia".
}

Nessa contextualização, procura-se transmitir o sentido do "jeito de ser guarani”, que se está conhecendo e aprendendo pela convivência, como que tecendo um texto em conjunto com os Guarani-Mbyá, dentro do enfoque hermenêutico, procurando o sentido do texto (falado, escrito, desenhado) e, ao mesmo tempo, de intensa amorosidade entre o pesquisador e pesquisados.

Os indígenas de Capivari do Sul estão em processo de ir e vir para uma ilha que fica localizada em Palmares do Sul, sob pressão dos fazendeiros, que os auxiliam no transporte e facilitam o seu assentamento nesta ilha. Alguns vão, permanecem um tempo lá, outros ficam na aldeia, como que demarcando esse espaço que já ocupam desde 1992, conforme manchete, Famílias de Índios Guaranis estão morando em Capivari, extraída de um jornal local de 02/09/1992. Observa-se o ir e vir, em busca do entendimento do querer deste povo, de modo que "[...] a compreensão deve ser entendida como parte da ocorrência de sentido, em que se formula e se realiza o sentido de todo o enunciado." (GADAMER, 1997, p.170). Visando compreender o modo de viver dos integrantes da TekoáAraçaty, olha-se a historicidade, o movimento de intensa comunicação, juntamente com a inteireza e territorialidade do povo (em diferentes aldeias).

Conversam ao redor do fogo, em longas contemplaçóes ou fumando o cachimbo (petynguá) com os indígenas do passado (espíritos). Realizam 
seus rituais de curas, bem como de passagem de uma fase do desenvolvimento humano para outra (menina-mulher) com o auxílio das outras aldeias, mantendo um forte laço entre os parentes, independente da filiaçẫo sanguínea. Essa vivência em sociedade constitui-os como um povo, uma nação, mantida por todos e por cada um, na preservação e conservação do "jeito de ser guarani".

\section{A comunicação entre os Guarani-Mbyá}

O guarani comunica-se pelo fazer, pelo exemplo, pelo silêncio e observaçáo do comportamento do outro, dentro da populaçáo pesquisada a grande maioria já fala com bastante fluência o português, observa-se a liberdade das crianças no falar as duas línguas, porém revelam a importância da manutenção do seu dialeto, sendo este, parte de sua identidade. Entre os membros da comunidade, observa-se o cuidado um com o outro, o respeito pelo funcionamento do outro, as crianças são orientadas sem gritaria, dentro de um viver harmônico e afetuoso. Entre os casais adultos, observa-se muita consensualidade, muito tempo para "fazer nada", simplesmente ficar juntos: falam pelo olhar, pelo silêncio e pelo contemplar, entregam-se ao momento presente, imitam os animais. Rubem Alves (2012, p.14-15) em uma de suas crônicas intitulada "Filosofia de Gato" diz:

Mas para meu gato nada falta. Ele é um ser completo. Por isso pode se entregar ao calor do momento presente sem desejar nada. E esse entregar-se ao momento presente sem desejar nada tem nome de preguiça. Preguiça é a virtude dos seres que estão em paz com a vida.

O guarani dentro de seu modo de viver, de sua cosmologia, do seu tempo, mantém paz, harmonia, caminham longas distâncias em contato com a natureza, os indígenas conversam entre si, as crianças obedecem aos adultos, as mulheres demonstram felicidade e simplicidade com os seus parceiros, agem sob sua autorização, seja pelo falar ou pelo olhar, quando querem conversar com tranquilidade utilizam sua língua materna; garantem no dialeto a preservação de seu viver e de sua cultura.

Nessa perspectiva de comunicaçáo, e, buscando a compreensão deste contentamento com o mundo, com a vida e com o outro, retorna-se aos conceitos de Gadamer que fala da relaçáo circular do todo e das partes, de forma que é o conjunto do povo, que habita em diferentes aldeias, que possibilita a compreensão o modo de ser, estar e viver do povo da 
TekoáAraçaty, a partir de sua historicidade ontológica, do viver dos antepassados, que cultuam e preservam pelos rituais de espiritualidade, ou seja, “[...] é o conjunto da Escritura Sagrada o que guia a compreensão individual - da mesma forma que ao inverso este conjunto só pode ser apreendido quando se realizou a compreensão individual." (GADAMER, 1997, p.179).

Somente olhando o todo consegue-se compreender a beleza do "gigante" encontrado através da força da fé, em sujeitos que moram em condiçôes totalmente adversas, sob o ponto de vista do mundo branco, mas mantêm-se unidos no modo de viver, jovens que continuam cultivando, dentro do possível, em virtude de ausência de um território demarcado, o viver dos antepassados; meninos que passam o dia na beira do rio, pescando e preparando seu próprio alimento, crianças que interagem e brincam tranquilamente com os diferentes tipos de animais que conseguem criar: ratão do mato, capivara, caturrita, galinha, patos e ema, entre outros.

Esse povo vive e convive dentro do conceito de humanidade, no sentido desenvolvido por Boff (2008, p.98): "[...] a visão do ser humano como ser-de-relaçóes ilimitadas, ser de criatividade, de ternura, de cuidado, de espiritualidade, portador de um projeto sagrado e infinito.", vivendo o que Boff (2008), denomina como um modo de ser-cuidado, através de reproduçóes do modo de vida ancestral, seja no carinho demonstrado na execução da tarefa de tirar piolhos um do outro, no auxílio entre os parceiros, e entre as diferentes geraçóes, no cuidado com os menores, no estar juntos em observação ou contemplação: ao ficarem no sol sentados ao lado das casas ou na beira da faixa, bem como em longos momentos de silêncio em volta do fogo, no preparo de alimentos, sempre acompanhados dos diferentes animais.

\section{ANCESTRALIDADE: O JEITO DE SER GUARANI-MBYÁ}

O ser humano é, simultaneamente, utópico e histórico-temporal. Ele carrega em si a dimensão Saturno junto com o impulso para o céu, para a transcendência, para o voo da águia (Júpiter). Nele se revela também o peso da terra, da imanência, o ciscar da galinha (Telus). É pelo cuidado que ele mantém essas polaridades unidas e faz delas material da construção de sua existência no mundo e na história. Por isso o cuidado é cuidado essencial. (BOFF, 2008, p.67).

$\mathrm{O}$ indígena Guarani vive essa dimensão céu/terra de forma muita intensa, por isto o seu modo de vida nos conduz ao modo de ser-cuida- 
$\mathrm{do}^{3}$, visto que se percebe uma intensa ligaçáo entre os membros da comunidade, especialmente, entre os membros de cada família. Sentam-se juntos, comem juntos, partilham do mesmo prato, compartilham do mesmo espaço com os animais, aquilo que, dentro do olhar de cultura branca, a cultura dita civilizada parece descuido ou sujeira, no viver do modo de ser Guarani é como se fosse parte deles; a terra não é suja, eles são a terra. Essa alteridade e pertencimento de que "nós somos assim" ou "nós não é assim", sustenta o sujeito e lhe confere a tranquilidade e o bem viver.

Neste capítulo, considera-se que o texto fotográfico revele mais a realidade do que o texto escrito, o que se constata pelas fotografias abaixo:

Figura1 - Beira da RS espaço de venda e recebimento de doaçôes.

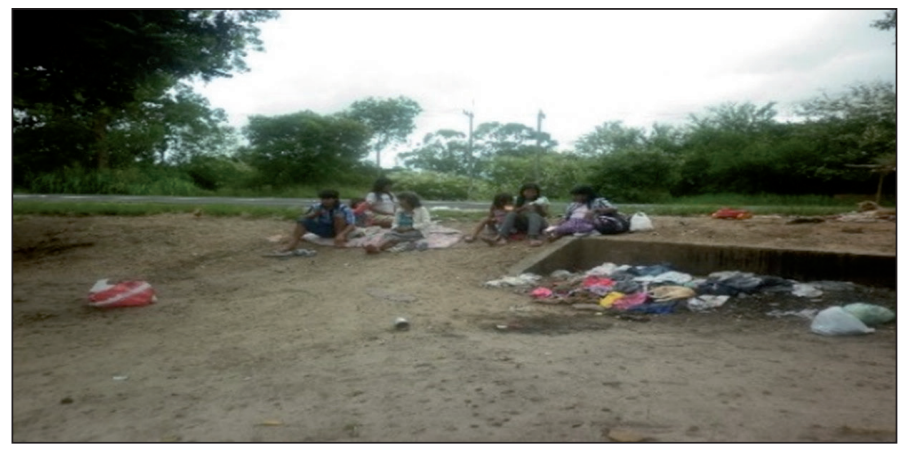

Fonte: Foto do autor.

O bem viver pode ser observado pelas suas expressóes faciais, pela forma tranquila como executam as suas atividades. A preocupação com a preservação da cultura está presente em todo o modo de viver, de forma muita intensa nos hábitos alimentares, sendo que estes só são mostrados, depois de muito tempo de convivência; pode-se dizer que depois que se adquiriu mais confiança e se faz (um pouco) parte da comunidade.

Nos primeiros dias, tudo o que se observava eram hábitos alimentares inadequados, de acordo com aquilo que recebem dos náo índios na beira da faixa: bolachinhas, doces e balas, entregues diariamente, diretamente às crianças. Nunca se observou nenhuma restrição pelos adultos no con-

\footnotetext{
3 Segundo Boff (2008, p.96) esse modo de ser no mundo, na forma de cuidado, permite ao ser humano viver a experiência fundamental do valor, daquilo que tem importância e definitivamente conta. Nâo no valor utilitarista, só para o seu uso, mas no valor intrínseco às coisas. A partir desse valor substantivo emerge a dimensão de alteridade, de respeito, de sacralidade, de reciprocidade e de complementaridade.
} 
sumo destes alimentos, ou qualquer regramento em virtude do horário (inadequado de acordo com os hábitos alimentares da cultura branca).

Depois de algum tempo de convivência:

Figura 2 - Preparo do tatu: alimento ancestral.

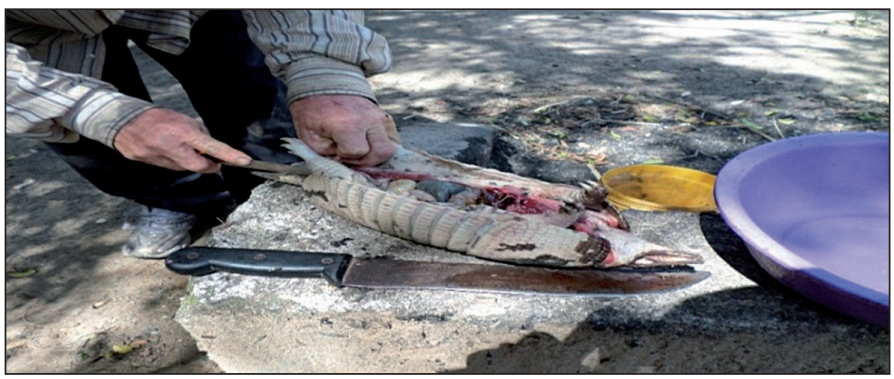

Fonte: Foto do Autor

Figura 3 - Preparo do pão caseiro, no forno improvisado com duas panelas: "é assim que fazemos".

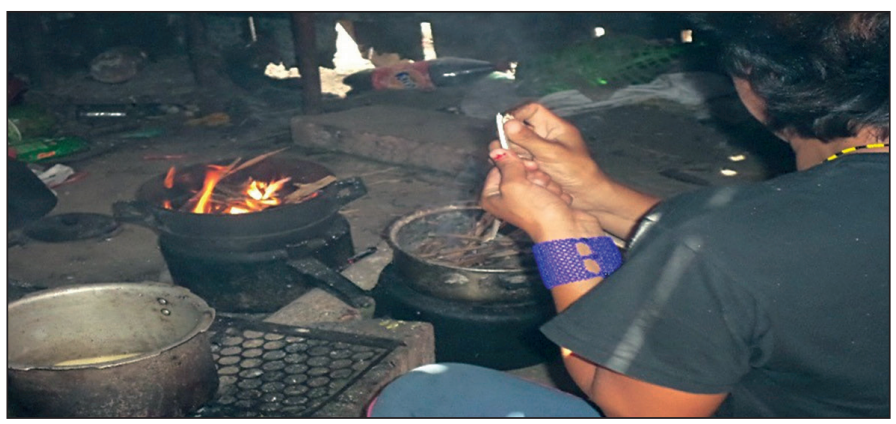

Fonte: Foto do Autor

\section{O ecomapa da aldeia}

O ecomapa consiste na representação através de desenhos dos contatos e relacionamentos que uma família ou instituiçẫo faz com seu entorno ou cidade, portanto é um instrumento que pode auxiliar no conhecimento ou entendimento da família, comunidade e suas relaçóes.

Segundo McGoldrick (2012, p.70) através do ecomapa 
[...] teremos condiçóes de investigar nossos palpites e intuições a respeito dos padróes familiares em um grande grupo de famílias e ver se nossas ideias se confirmam ou então descobrir que estavam faltando nas relações entre as conexões humanas e saúde, resiliência e criatividade.

Com o apoio do ecomapa busca-se entender e conhecer os pontos de apoio da comunidade em estudo com a cidade, visto que historicamente o indígena foi excluído das políticas públicas, bem como dos direitos sociais. Portanto, a realização do ecomapa constitui-se numa tarefa também de verificar que visibilidade tem hoje o indígena no mundo não indígena, como o povo da aldeia está dialogando com a cidade? Busca-se, ainda, com a produção do ecomapa da aldeia clarificar o papel da mulher o do homem, dentro da família e da comunidade; verificando que se antigamente era delegado ao homem a busca da caça e a exploração da selva, hoje mantém-se esse costume: o homem vai à cidade para as compras e com mais frequência faz a tarefa de buscar a lenha para o fogo.

A figura a seguir apresenta os pontos de diálogo da comunidade com a cidade, centralizados na figura do cacique, representando o papel do homem dentro da cultura indígena, como aquele que cuida da interlocução com o mundo não indígena, buscando a garantia das políticas de atendimento para toda a comunidade, bem como os gêneros alimentícios.

Figura 4 - O Ecomapa da Aldeia

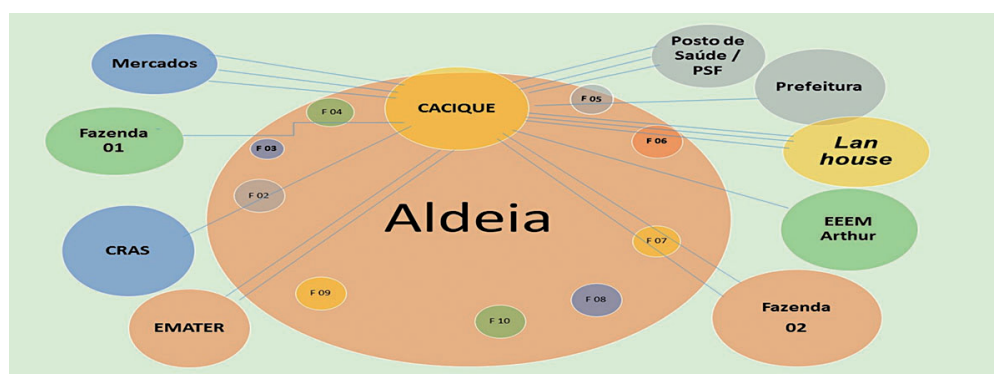

Fonte: Elaboração própria.

O ecomapa representa a percepção dos vínculos entre os integrantes da aldeia, para além das entrevistas e dos questionários estruturados, pois, segundo Thiollent (1988), os questionários e entrevistas na pesquisa-ação trazem informaçóes sobre o universo que deverão ser analisados e discutidos com os integrantes do grupo ou comunidade; nesta perspectiva 
todas as impressóes de conflitos foram também discutidas com alguns dos membros dentro dos contextos e situaçóes vivenciadas durante o período de pesquisa e docência.

Destaca-se que, em alguns momentos, a pesquisadora sente-se perpassado pelos seus próprios legados familiares, pois também é originária de uma estrutura familiar em que as relaçóes eram estabelecidas conforme modelo patriarcal, no qual o poder de decisão é centralizado na figura do pai ou do mais velho, que fica, na sua ausência daquele, como representante.

\section{A construçáo do genograma com as famílias da aldeia Araçaty}

O genetograma ou genograma é muito utilizado pelos terapeutas de família, assim como pelas equipes de saúde da família como um instrumento capaz de mapear não somente os membros, mas os ciclos de doenças e patologias que incidem na população, podendo ser de grande auxílio para o atendimento da complexidade do viver atual, nas diversas formas de organização familiar, pois conforme McGoldrick (2012, p.113): "A questão inicial é que o rastreamento dos padrôes familiares ao longo do tempo, mais do que simplesmente focar sobre um indivíduo, é uma estrutura crucial para a compreensão da experiência humana no contexto da história."

A elaboração do genograma auxilia a pensar sistemicamente, olhar as partes e o todo, olhar as relaçôes entre os membros e para além dos membros, busca compreender como este grupo familiar interage com a comunidade onde está inserido e com a sociedade envolvente. Quais são seus padrốes de comportamento? Suas narrativas? Que padróes de saúde e doença desenvolveram ao longo de sua história?

Trata-se de uma ferramenta que possibilita o transitar intergeracional, ou seja, olhar a situaçáo no presente e buscar suas origens no passado, ou olhar o passado para compreender o funcionamento do sujeito ou do grupo na atualidade.

O que faz do genograma um instrumento táo rico é que as informaçốes são corrigidas e ampliadas à medida que o terapeuta vai sabendo mais sobre a história da família. Assim, com o passar do tempo, o genograma se transforma em um mapa mais preciso e abrangente da história familiar. (McGOLDRICK, 2012, p.38). 
McGoldrick diz que se deve incluir na construção/produção dos genogramas, pelo menos três geraçôes de membros da família, juntamente com os "nós", ou seja, os pontos críticos da história familiar, particularmente em relação ao ciclo vital, que pode ser complementada pela cronologia da família, registrada a partir de suas narrativas: casamentos, nascimentos, mortes, entre outros.

Para que se possa ter a visualização real da família, torna-se necessário que o genograma mostre não apenas os membros biológicos, mas também a rede de amigos e comunidade, tanto no presente como no passado, a fim de poder observar os padróes repetitivos, esperanças, crenças e cultura familiar, na busca do conhecimento e compreensão da alteridade de cada sujeito e do grupo enquanto família.

Silva e Lopes (2014, p.10) em seus estudos sobre a hermenêutica de Gadamer trazem a compreensão através de uma estrutura circular, de forma que para compreendermos o fenômeno do ser, ou de um acontecimento, torna-se necessário o contexto e sua historicidade; "Se compreender é pré-compreender, esse processo se verifica em uma perspectiva histórica. A compreensão se dá sob uma vigilância histórica. "

Pensar em elaborar o genograma de famílias indígenas perpassa fronteiras culturais e o enfrentamento de preconceitos que cegam. Assim, nesta perspectiva é que se busca a compreensão hermenêutica desses genogramas, que passam a ter um caráter infinito, devido à tradiçáo cultural e historicidade destes sujeitos, bem como a necessidade de abertura de novos horizontes para o olhar do pesquisador, fechado ao longo da formação pessoal e profissional, enquanto sujeito do mundo não indígena.

Neste sentido, somente a consciência dessa ambivalência entre o que se vê: estranhezas e familiaridades, com esse modo de viver/conviver em família e comunidade, num processo de ser com o outro, onde o outro também é um tu diferente do eu, é que se torna possível a construção de uma "leitura" da realidade que fale de um "nós", enquanto seres humanos e da "nossa" humanidade.

Essa alteridade dialógica permite esclarecer o horizonte compreensivo, os preconceitos dos mal-entendidos, a saber, aqueles que se fecham à interpretação, à distância temporal ou a mobilidade histórica da coisa, tornando-se rígidos e perdendo a sua funcionalidade, nos tornam surdos para a coisa de que nos fala a tradição. São os preconceitos não percebidos que originam alienação, bloqueando-nos em nossa capacidade de ouvir a tradiçấo: estes são de fato os preconceitos falsos ou 
ilegítimos que, por não se colocarem em questão, induzem o erro da compreensão. (SILVA; LOPES, 2014, p.10).

A seguir, apresenta-se o genograma para que seja olhado dentro da perspectiva sistêmica, à luz da hermenêutica, dialogando com o passado e com o presente, para que, para além dos entrelaçamentos familiares atuais, possa-se estar aberto para os entrelaçamentos de vida e morte, para os costumes e sofrimentos do povo Guarani-Mbyá, observando e analisando todos os membros de forma interligada com a contemporaneidade e historicidade, de como se deu a construçáo social brasileira, que lugares tiveram e têm as diferentes etnias em nosso país.

Dentro do conceito trazido por McGoldrick (2012, p.32): "Família é aqueles que estão ligados através de sua história biológica, legal, cultural e emocional e pelo seu suposto futuro juntos."; considerar-se-á comunidade da TekoáAraçaty uma grande família, originada por duas matrizes, do patriarca cacique Augusto da Silva Benites e da matriarca Liliana Gimenes Brisuela.

Os genogramas foram elaborados por núcleo familiar (conforme moradia) e posteriormente, em duas grandes famílias, já apresentando a intensa ligação entre os membros, bem como as relaçôes de obediência dos mais novos para com os mais velhos, a partir das observaçóes, vivências e anotaçóes do diário de campo, juntamente com a análise das entrevistas estruturadas, tendo como legendas dos diagramas a representação do quadro abaixo:

Figura 5 - Legenda dos Diagramas

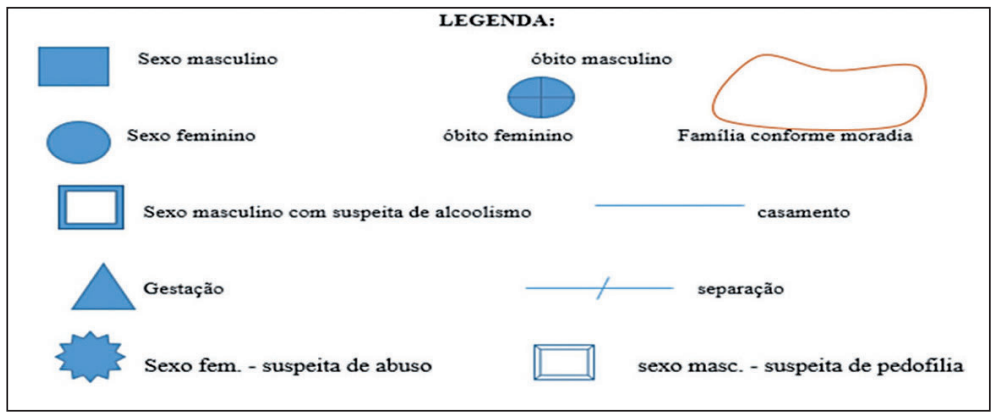

Fonte: Elaboração própria. 
Figura 6 - Genograma apresentado o cruzamento entre as duas famílias

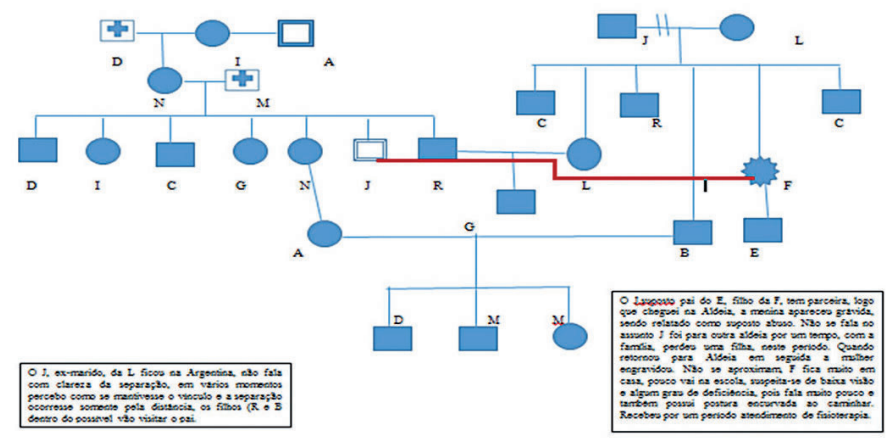

Fonte: Elaboração própria.

\section{A organizaçáo e as funçóes familiar na cultura Guarani-Mbyá}

As famílias Guarani-Mbyá estão organizadas em torno do mais velho, independente de gênero, na população em estudo, sendo a Aldeia uma grande família, também demarcada de acordo com a ocupação territorial. A partir da elaboração do genograma e imersão no cotidiano da comunidade da TekoáAraçaty, observou-se que de fato a aldeia constitui-se numa grande família, na qual os membros possuem funçóes de acordo com o nome recebido no ritual de "dar nome às crianças", e, então, a pessoa vai sendo construída durante todo o seu desenvolvimento na escuta das "belas palavras" dos mais velhos, procurando cuidar-se para corresponder ao desejo do deus que o enviou ao mundo, visto que sua missáo na terra está acorrentada e este deus.

A organização da disposição das casas no espaço físico que ocupam mostra as subdivisóes familiares. No grupo em estudo, aparece claramente à proximidade das casas pela descendência genética e, ao mesmo tempo, a independência; quando, segundo o observador, há possibilidade da constituição de uma nova aldeia. $\mathrm{Na}$ comunidade observada, o filho mais velho da família chefiada pela matriarca, estrategicamente fica do outro lado da RS 040, sendo que os filhos do cacique ficam todas em torno da casa deste.

Este chefe de família $(\mathrm{R})$, em vários momentos, apresenta conflitos com o cacique e demonstra sua independência. Não faz movimentos de 
enfrentamento ou rebeldia, mas mantém-se afastado, cuidando da sua família, sempre em diálogo com a mãe (L). A família de (L), que habitava uma das casas mais afastada, da casa do cacique, com a migração da família de (I) para outra aldeia, localizada na Granja Vargas, em virtude de necessidade de voltar a plantar, acredita-se que pela necessidade de subsistência, mas também motivada pela crença de que a atividade de plantio está relacionada à manutenção da saúde, visto que desde o ano passado trata problemas de diabete, passou a habitar a residência que ficou vazia.

Fica evidente que cultivam um viver comunitário, com fortes vínculos sociais e de reciprocidade entre os membros, mas que cada família é responsável pela nutrição de seus descendentes em todos os sentidos: alimentação, educação e cultura.

Em 2013, quando se tinha pouco tempo de convívio e a forte crença pessoal de que a aldeia era uma grande família, observa-se através da distribuição de picolés, que uma indígena, embora tivesse picolés sobrando, inclusive oferecendo à pesquisadora, para uma criança que pediu disse: "Vai pedir para tua mãe, tua mãe é que tem que te dar". Atualmente, faz-se a leitura desta fala como responsabilização da mãe e do pai com a nutrição do filho.

As culturas indígenas não estão paradas no tempo, fizeram-na parar, ou pelo menos tentaram. Como toda cultura, os indígenas vão se transformando em funçáo de novos elementos ou acontecimentos e novas situaçôes. À medida que a realidade se transforma, o índio busca novos símbolos que possam traduzir o significado das novas realidades, o fato de consumir produtos industrializados, de dominar novos conhecimentos não faz com que uma sociedade deixe de ser indígena. (SILVA; PIOVEZANA, 2013, p.49).

Neste cenário da atualidade, com ausência de terra, considerada pelo povo Guarani-Mbyá como primeira necessidade para o bem viver e criação dos filhos, buscam alternativas, convivem e aceitam aquilo que chega do mundo não indígena, através de doaçôes (roupas, alimentos, entre outros), recebidas pelas crianças e pelas mulheres, enquanto os homens permanecem afastados, sempre em permanente vigilância. Possuem fortes tradiçôes culturais que mantêm sob um cultivo velado, oculto dos olhos de quem chega por uma "cortina de lixo", estáo unidos no compromisso de criar e educar seus filhos para sobrevivência, para o náo esquecimento dos ensinamentos ancestrais, assim como para a convivência com a tecnologia e os saberes do mundo não indígena. 
Em diálogo com o cacique sobre os apontamentos dos genogramas, aquilo que dentro da cultura náo indígena seria considerado como abuso, fica nítido a interlocução com o mundo branco:

Nós já sabemos que a moça precisa respeitar, o homem também tem que pensar, mas se acontece o homem tem que assumir. Criança não nasce sem pai. Metade nossa lei e metade do branco, todo mundo tem que saber o que é certo. (Diário de Campo, agosto, 2015).

A grande tarefa da família, dividida em harmonia entre o casal, está na criação dos descendentes, de acordo com as regras da cultura, vivendo em reciprocidade, em igualdade, em harmonia e respeito aos deuses e ancestrais, escutados pela contemplação, no convívio com a natureza, num contexto pleno de amorosidade. Celebram com frequência os aniversários, dias de festa e beberagem, mas conscientes que precisam estar alerta para não errar, para corresponder ao nome recebido em criança, vivem o hoje, agradecem a cada dia quando o sol os acorda e a cada noite que alcançam, dividem seus alimentos com os animais e com a terra, pois neles estão seus ancestrais, cultivam a inspiração e ensinam sabedoria, paciência, esperança e confiança num mundo mais humano e respeitoso; um "lugar bom para se viver".

\section{Consideraçóes finais}

O conhecimento da cultura, dos rituais e crenças da comunidade Guarani-Mbyá, no contexto de convivência, e, a construção de um vínculo de afetividade e confiança entre pesquisadora e pesquisados, faz com que esta pesquisa se apresente como ferramenta para intervenção social de visão sistêmica, conforme pressupostos da Terapia Familiar Sistêmica e pressupostos da pesquisa-ação, através do registro fotográfico, observaçôes, realização das atividades escolares, rodas de conversa, elaboração de genogramas familiares e ecomapa. A pesquisa nos possibilitou sair de uma concepçáo cartesiana, na medida em que transcendeu a lógica da dominação e controle do objeto, ou a fragmentaçâo do sujeito, sem a interlocução com sua identidade cultural e ontológica.

Ao "mergulhar" num mundo diferente e ir à busca do conhecimento do viver do outro, inicia-se um processo de produção de saberes que instituem identidades; identidades novas, constituídas a partir do convívio, de forma que ambos são afetados pelo encontro. A partir daí surgem novas crenças, quebram-se estereótipos, surgem novos mecanismos de adapta- 
ção, de forma que ambos os atores envolvidos no processo - pesquisadora e pesquisados - saem fortalecidos. Hoje, consegue-se perceber o quanto a estrutura comunitária e familiar é responsável pela resiliência e resistência destes sujeitos, tanto em suas individualidades, quanto na coletividade. $\mathrm{Na}$ expressão: "nós somos assim", sentem- se inteiros, tem um povo e uma cultura, podem conviver com a sociedade envolvente, usufruir de seus recursos tecnológicos, mas voltam para o mato, mantêm a harmonia com a natureza e preservam o seu modo de viver.

O genograma e o ecomapa como ferramentas de pesquisa revelaram a organização familiar, a força comunitária e sua interlocução com a sociedade envolvente, possibilitando o entendimento de que o indígena, na atualidade, precisa de muito amparo para resistir as adversidades do cotidiano. Parte do alimento precisa ser adquirido nos mercados, a saúde das crianças está condicionada a parte do medicamento dos não indígenas, porém sua sobrevivência,também, está interligada com a manutenção da cultura ancestral, é através de seus rituais e crenças que mantém o bem viver e a alegria, num território que se constitui não somente do espaço físico, mas num espaço mítico, cosmológico e ancestral.

Percebe-se, que há muito a se desvendar, no tempo que permitirem, de acordo com a confiança e avanço das políticas públicas. Em uma sociedade globalizada como a que vivemos, os indígenas precisam de políticas públicas que de fato sejam efetivas na preservação de sua identidade. A ausência de políticas públicas efetivas e de território dificulta tanto a preservaçáo da identidade, quanto a sustentabilidade dos mesmos nos ambientes aos quais estáo inseridos, sendo assim, acabam ficando a margem da sociedade, num campo de vulnerabilidade muito grande.

Mas, há muito para surpreender-se, consigo mesmo e com esse outro, possibilitando a revelação da grandeza (divindade) e imperfeição humana. Portanto, este estudo se constitui em primeiros passos, de forma que a mente foi capaz de processar o ensinamento, conforme a personalidade da pesquisadora, de acordo com os valores existenciais e familiares que carrega. Hoje se está mais atento, observa-se mais, respeita-se infinitamente a sabedoria deste povo...

Permanece o desejo de aprender, de revelar-se, de conviver, "estar junto", caminhar para uma Terra/sociedade de mais harmonia, de mais fraternidade para que as famílias, das diferentes etnias, possam continuar recebendo a confiança de Deus/Nhanderu, Nosso Pai Primeiro, para criar e educar seus filhos, como expressa o canto Guarani-Mbyá (YVÝ POTY, 2012, p.59): 


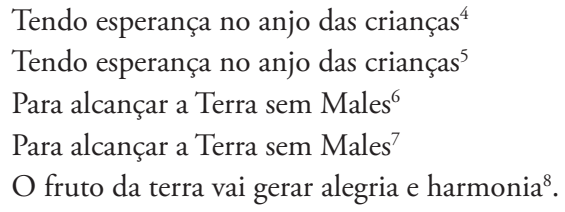

\section{Agradecimento}

A mestre Marli Olina de Souza o nosso reconhecimento, ter tido oportunidade de conviver e escrever um artigo sob a sua orientaçáo foi uma experiência ímpar; um ato de cuidado comigo, momento de renovação, em que tive oportunidade de aprender, trocar e crescer. Somente alguém muito especial, que lia pessoas e textos com os olhos do coração, nos oferece essas oportunidades.... Muito obrigada!!!! Nosso encontro foi uma experiência constitutiva de espiritualidade e fortalecimento.

\section{THE GENOGRAM FAMILIES CONSTRUCTION GUARANI-MBYA: A STRATEGY FOR STRENGTHENING AND RECOGNITION OF AN INDIGENOUS COMMUNITY CULTURE ANCESTRAL}

ABSTRACT: The survey was conducted on a Guarani community on the banks of the RS 040, in Capivari do Sul / RS, with a community of 40 individuals, who are in situation of social vulnerability and culture. It is a search that is a descriptive qualitative approach, which uses the structuralistfunctionalist method (PARSONS, 1902-1979) and (MERTON, 19102003) for research and action research (TIOLLENT, 1947) as a methodology for theoretical and practical articulation and analysis of ethnographic research data. It is used as a tool to build the family genogram (MC Goldrick, 2012) and ecomap (MC Goldrick, 2012) of the community, guided by a structured questionnaire aimed at listening to the voice of these subjects. Data analysis brings hermeneutical and semiotic reflections in the light of the concepts

\footnotetext{
4 Nhambojeroviákyringüénhee

5 Nhambojeroviákyringüénhee

6 Yvýju mirim jaupityaguã

7 Yvýju mirim jaupityaguã

8 Jaupityaguã
} 
of Gadamer (1900 - 2002) and Peirce (1839-1914), for a historical and cultural perspective, establishing a dialogue with the authors of Systemic Family Therapy. Finally, in concluding remarks, the cultural importance of the Guarani to contemporary society as well as the possibilities of using the genogram as a service tool for communities and families, both in the therapeutic approach, as for formulation and structuring of public policies.

KEYWORDS: Culture. Guarani. Family. Genogram. Indigenous community.

\section{REFERÊNCIAS}

AgOSTINHO, M. Ecomapa. Revista Portuguesa de Medicina Geral e Familiar, Lisboa, v.23, n.3, p.327-30, maio 2007. Disponível em: <http://www.rpmgf.pt/ojs/index.php/rpmgf/article/view/10366>. Acesso em: 18 out. 2014.

ALVES, R. Pimentas: para provocar incêndio, não é preciso fogo. 1.ed. São Paulo: Planeta, 2012.

BOFF, L. Saber cuidar: ética do humano - compaixão pela terra. 14.ed. Petrópolis: Vozes, 2008.

COSTA, M. V.; GRÜN, M. A aventura de retomar a conversação Hermenêutica e pesquisa social. In: COSTA, M. V. (Org.). Caminhos investigativos I: novos olhares na pesquisa em educação. 3.ed. Rio de Janeiro: Lamparina, 2007. p.83-102.

CHAMORRO, G. Língua e identidade: desafios da palavra Guarani ao TekoArandu. Disponível em: <http://www.djweb.com.br/historia/ arquivos/gracielachamorro.pdf>. Acesso em: 10 ago. 2014.

GADAMER, H.-G. Verdade e método. Tradução de Flávio Paulo Meures. Petrópolis: Vozes, 1997.

McGOLDRICK, M. Genogramas: avaliação e intervenção familiar. Tradução: Sandra Maria Mallman da Rosa; revisão técnica: Cynthia Ladvocat. 3.ed. Porto Alegre: ARTMED,2012.

SILVA, A. F.; LOPES, M. do C. Experiência Hermenêutica em Gadamer: da reabilitação dos preconceitos ao conceito de experiência hermenêutica. 
Peri, Florianópolis, v.6, n.1, p.1-18, 2014. Disponível em: <www.nexos. ufsc.br/index.php/peri/article/download/904/407>. Acesso em: 25 nov. 2016.

SILVA, Z. C. da; PIOVEZANA, L. A cultura no cotidiano indígena: identidade e pertencimento. In: BENTUVI, J.; BERGAMASCHI, M. A.; MARQUES, T. B. I. (Org.). Educação indígena sob o ponto de vista de seus protagonistas. Porto Alegre: Evangraf, 2013. p.42-52.

THIOLLENT, M. Metodologia da pesquisa-açáo. São Paulo: Cortez: Autores Associados, 1988.

YVÝ POTY, Y. Flores e frutos da terra: cantos e danças tradicionais Mbyá-Guarani. Organizado por Maria Elizabeth LLucas e Marília Stein. Porto alegre: Iphan/Grupo de Estudos Musicais/PPGMUS/UFRGS, 2012 . 